\title{
Smokeless Tobacco Expectancies Among a Sample of Rural Adolescents
}

\author{
Ian M. Newman, PhD, FAAHB; Duane F. Shell, PhD
}

\begin{abstract}
Objective: To examine the role of expectancies in adolescent smokeless tobacco (ST) use. Methods: Self-report measures of students' ST expectancies, cigarette and ST use, and peer and family tobacco use were collected from a sample of 978 rural high school students. Results: Student expectancy beliefs significantly predicted ST use and intention to try $S T$ in the next year. Student ex-
\end{abstract}

pectancies about ST were influenced by gender, cigarette use, and peer tobacco use. Familymember tobacco use did not strongly affect expectancies. Conclusion: Expectancies play a meaningful role in students' current and future decisions whether to use ST.

Key words: smokeless, spit tobacco, expectancies, rural adolescents

Am J Health Behav. 2005;29(2):127-136
$\mathrm{E}$ xpectancies are the anticipated outcomes of a particular behavior., ${ }^{1,2}$ Smokeless tobacco (ST) expectancies are the anticipated outcomes of using ST. Expectancy theory is one version of a number of related theories concerning the cognitive mechanism by which early learning experiences influence later behavior choices. Expectancies have been found to be strong predictors of behavior. This paper describes the relationship between ST expectancies and the behavior of the sample of rural adolescents.

Over the past several decades there has been an apparent increase in the use of ST among adolescents. At the same time there has been little research on adolescent ST use. What research there has been suggests that the dynamics of ST

Ian M. Newman, Professor; Duane F. Shell, Research Associate Professor, Department of Educational Psychology and The Nebraska Prevention Center for Alcohol and Drug Abuse, University of Nebraska-Lincoln, Lincoln, NE.

Address correspondence to $\mathrm{Dr}$ Newman, $\mathrm{Ne}$ braska Prevention Center for Alcohol and Drug Abuse, University of Nebraska-Lincoln, Box 880345, Lincoln, NE 68588-0345. E-mail: inewman1@unl.edu use may differ from cigarette smoking. ${ }^{3}$

\section{Prevalence}

Like cigarette smoking, national surveys suggest that ST use may be on the decline. The Youth Risk Behavior Surveillance System suggests that in 1995, 11.4\% of students in grades $9-12$ had used ST or snuff on one or more of the past 30 days. In 2001 this proportion was $8.2 \% .{ }^{4}$ The Centers for Disease Control reported in 2002 that $6.6 \%$ of the high school population had used ST in the last 30 days. ${ }^{5}$

Gender differences were significant. The YRBSS for 2001 reported that $14.8 \%$ of the males and $1.9 \%$ of the females had used ST in the last 30 days. ${ }^{6}$ The Centers for Disease Control reported in 2002 that $10.8 \%$ of the high school males and $1.4 \%$ of the high school females had used ST in the last 30 days. $^{5}$ Lifetime use was significantly higher. Among high school students, the 1999 National Youth Tobacco Survey estimated that $28.5 \%$ of the males and $7.6 \%$ of the females had tried ST at some time in their lifetime. ${ }^{7}$

\section{Onset}

Studies of the age of first ST use suggest that adolescence is an important period for establishing ST use patterns. 
Riley et $\mathrm{al}^{8}$ found that $12 \%$ to $14 \%$ of adult ST users recalled beginning their use of ST before the age of 12 . Creath et $\mathrm{al}^{9}$ reported that $77 \%$ of those who had tried ST had done so by the age of 14 . These findings are similar to those of Simon et $\mathrm{al}^{10}$ who reported that $24 \%$ of their sample had tried ST the summer between seventh and eighth grade. Around the ninth grade seemed to be the time of initial onset of ST use.

Age of onset is important because the duration of use increases addiction rate and increases the risk of long-term health problems. Riley et $\mathrm{al}^{11}$ reported that longer and more frequent use greatly increased the likelihood the user would be addicted. Early onset increased the chances of continued use throughout adolescence and adulthood. ${ }^{8,9}$ Continued ST use appears to increase the use of smoked tobacco, alcohol, and other drugs. . $^{3,9,10}$ Understanding the factors that influence adolescent ST use, therefore, is especially important for intervention and prevention programming.

\section{Determinants}

The few available studies of ST use suggest that most adolescent users are white males. One of the most important determinants of ST use was reported to be peer use. Several studies have presented data to support this conclusion. Boyle et al, ${ }^{12}$ Creath et al, ${ }^{9}$ Horn et al, ${ }^{13}$ and Kury et $\mathrm{al}^{14}$ all reported that a person is more likely to try ST if he had a friend who used. Other significant determinants included family use (parent or sibling), favorable attitudes towards use, and inflated perceptions of the importance of tobacco use. ST users tended to be more prone to higher rates of other risky behaviors. ${ }^{10}$

Many ST users felt that sanctions (consequences/punishment) for ST use from schools and parents were minimal., $9,12,15$ Many adolescent users used ST at home and started their use in the presence of family members. Smokeless tobacco users reported few consequences for their use at school and home. They also report that it was easy to obtain ST from stores, peers, or family members. Students reported that school rules about ST use were rarely enforced, and they viewed the punishment as minimal for tobacco use at school..$^{9,12,15}$

\section{ST and other Substance Use}

$\mathrm{Hu}$ et $\mathrm{al}^{3}$ have suggested that cigarette smoking and ST represent 2 different locations on the drug continuum and should, therefore, be treated separately. The use of one does, however, greatly increase the use of the other. ST use and cigarette smoking are highly correlated. Studies suggest that ST use may be a gateway to cigarette smoking or other drugs or vice versa. $3,9,10$ The most common comorbid use with ST is cigarette smoking. ${ }^{3}$ People who use any form of tobacco are at a much greater risk for the use of other substances. . $^{3,9,10}$

\section{ST Expectancies}

Expectancies concerning the outcomes of a behavior have been found to be potent predictors of that behavior. A considerable body of work has found that expectancies influence alcohol use. ${ }^{1,2,16}$ A smaller, but growing, literature has identified expectancies as important factors in smoking. ${ }^{17-19}$ We found only 2 studies ${ }^{20,21}$ that examined expectancy influences on ST use. These studies suggested initial evidence that outcome expectancies were a determinant of ST use. However, a significant gap remains in our understanding of how expectancies affect adolescent ST use and how expectancies interact with other known influences on ST use such as smoking and family and peer tobacco use patterns.

\section{The Present Study}

The limited amount of research in the last 10 years on ST use contrasts with the large amount of research on adolescent smoked tobacco use. The Centers for Disease Control and Prevention can now advocate the use of school curricula to prevent and reduce smoked tobacco use, based on the quantity of quality science. Data on ST are not sufficient to make similar recommendations. The objective of this study was to increase our understanding of the dynamics of adolescent ST use, focusing especially on the role of expectancies in current and intended ST use.

\section{METHODS}

\section{Study Population}

We recruited 978 high school students from 10 rural Nebraska high schools (518 female; 458 male; 2 unstated; 296 freshmen, 243 sophomores, 267 juniors, and 131 seniors; 41 not reporting grade). Students were classified as users of ST if 
they reported using ST one or more times in the past 30 days. There were $176 \mathrm{ST}$ users $(18.0 \%), 6.0 \%$ females and $31.5 \%$ males.

Schools were selected purposely to provide reasonable representation of the rural parts of the state and to have an adequate enrollment to justify data collection. Classes were selected at random to provide approximately 100 students per school. Data were collected by a member of our staff who followed a standard protocol. No teachers or other school personnel were involved in data collection, and no school personnel saw the completed questionnaires. Responses were anonymous, and students were assured confidentiality. The project was approved by the university's research review board. Schools observed their own policies for informing parents about the study.

\section{Expectancy Measure}

Adolescent ST expectancies were elicited during focus group discussions with groups of 5 to 12 students in 4 rural high schools in 4 different regions of Nebraska. These discussions led to the creation of an inventory of more than 100 expected outcomes from ST use. The outcomes were rewritten as expectancy statements. The list of expectancy statements was revised and reworked several times by a team of researchers experienced in expectancy questionnaire development. The resulting questionnaire contained 38 expectancy items. These items were pilot tested with high school students for clarity of meaning.

\section{Other Measures}

The questionnaire contained demographic questions and questions about personal, family, and peer use of ST and cigarettes. Questions from the 1999 Youth Risk Behavior Survey ${ }^{22}$ about lifetime and last-30-day use of ST and cigarettes were used to measure behaviors.

\section{Statistical Analysis}

Using a random split-half sample of 489 students, the expectancy items were factor analyzed with exploratory factor analysis using principal components extraction with Varimax rotation. This analysis resulted in the identification of 5 factors and the elimination of 18 poorly fitting items. Using the second half of the split sample (489 students), a confirmatory factor analysis was done to verify the adequacy of the identified factors. Results confirmed the adequacy of the 5factor solution and item-factor fit.

The 20 expectancy items were measured on a 7 -point Likert scale $(1=$ strongly agree, $2=$ agree, $3=$ somewhat agree, $4=$ neither agree nor disagree, $5=$ somewhat disagree, $6=$ disagree, and $7=$ strongly disagree). The 5 identified subscales were

- safety and convenience (5 items, alpha $=.84 ;$ eg, If I chew, my boss will be happier than if I smoke. If I use chew when I am working on my job, I will be safer than if I smoke.);

- physical pleasure (3 items, alpha = .78 ; eg, If I chew tobacco, it will relieve stress in my life. If I chew, it will taste good.);

- effects on peers (4 items, alpha $=.73$; eg, If I chew, I will not harm others like smoking does. If I chew around my friends, it will not bother them like smoking.);

- image (4 items, alpha $=.77$; eg, If I chew tobacco, I will look cool. If I do not chew tobacco, my friends will make fun of me.); and

- negative consequences (4 items, alpha $=.59$; eg, If I chew, my girlfriend/ boyfriend will not approve. If I chew, I will waste a lot of money.).

Scores were computed by taking the mean score of the items in the subscale.

Factors influencing current ST use were determined using logistic regression. Linear regression analysis was done to predict future ST use. Analyses of group differences used t-tests. An Alpha level of .05 was used for all significance tests. Cohen's d was used for effect sizes for between-group comparisons. All analyses were done with SPSS for Windows V. 11.5 .

\section{RESULTS \\ Relations Between Expectancies and Students' Use and Intentions to Use ST}

ST users had significantly more positive and less negative expectancies about ST than did nonusers (Table 1). The effect sizes for the physical pleasure and effects on peers scales exceeded 1 standard deviation and for the safety and convenience and image scales approached 1 standard deviation. Even though smaller, the effect size for negative consequences approached two thirds of a standard deviation. Interestingly, for the physical plea- 
Table 1

Students' Mean Scores on Expectancies by ST Use

\begin{tabular}{|c|c|c|c|c|c|c|c|}
\hline & \multirow[b]{2}{*}{ df } & \multicolumn{2}{|c|}{ ST User } & \multicolumn{2}{|c|}{ Non-User } & \multirow[b]{2}{*}{$\mathbf{t}$} & \multirow{2}{*}{$\begin{array}{c}\text { Cohen's } \\
\text { d }\end{array}$} \\
\hline & & $\mathbf{M}$ & SD & $\mathbf{M}$ & SD & & \\
\hline Safety and Convenience & 224.90 & 4.28 & 1.56 & 5.58 & 1.22 & $10.41 * * *$ & .94 \\
\hline Physical Pleasure & 207.55 & 3.95 & 1.75 & 5.98 & 1.11 & $14.79 * * *$ & 1.38 \\
\hline Effects on Peers & 266.83 & 2.96 & 1.32 & 4.58 & 1.37 & $14.62 * * *$ & 1.08 \\
\hline Image & 205.81 & 5.53 & 1.34 & 6.42 & .83 & $8.53^{* * *}$ & .89 \\
\hline Negative Consequences & 246.21 & 2.72 & 1.25 & 1.97 & 1.15 & $-7.30 * * *$ & .62 \\
\hline
\end{tabular}

Note.

ST Users, $n=176$; Nonusers, For Safety and Convenience and Effects on Peers, $n=785$; for all others, $n=786$. For all tests, unequal variances were assumed. Cohen's $d=$ effect size in standard deviation units.

$* \mathbf{P}<.05$. $* * \mathbf{P}<.01 . \quad * * * \mathbf{P}<.001$.

sure and effects on peers scales, ST users and nonusers not only differed relative to one another but also had mean scores on opposite sides of the Likert midpoint. This suggested that ST users, on average, agreed with these expectations whereas nonusers disagreed.
We examined the association between students' expectancies and current ST use. We used logistic regression to predict whether the student had used ST in the past 30 days. To examine expectancy influences relative to other student and demographic characteristics that might

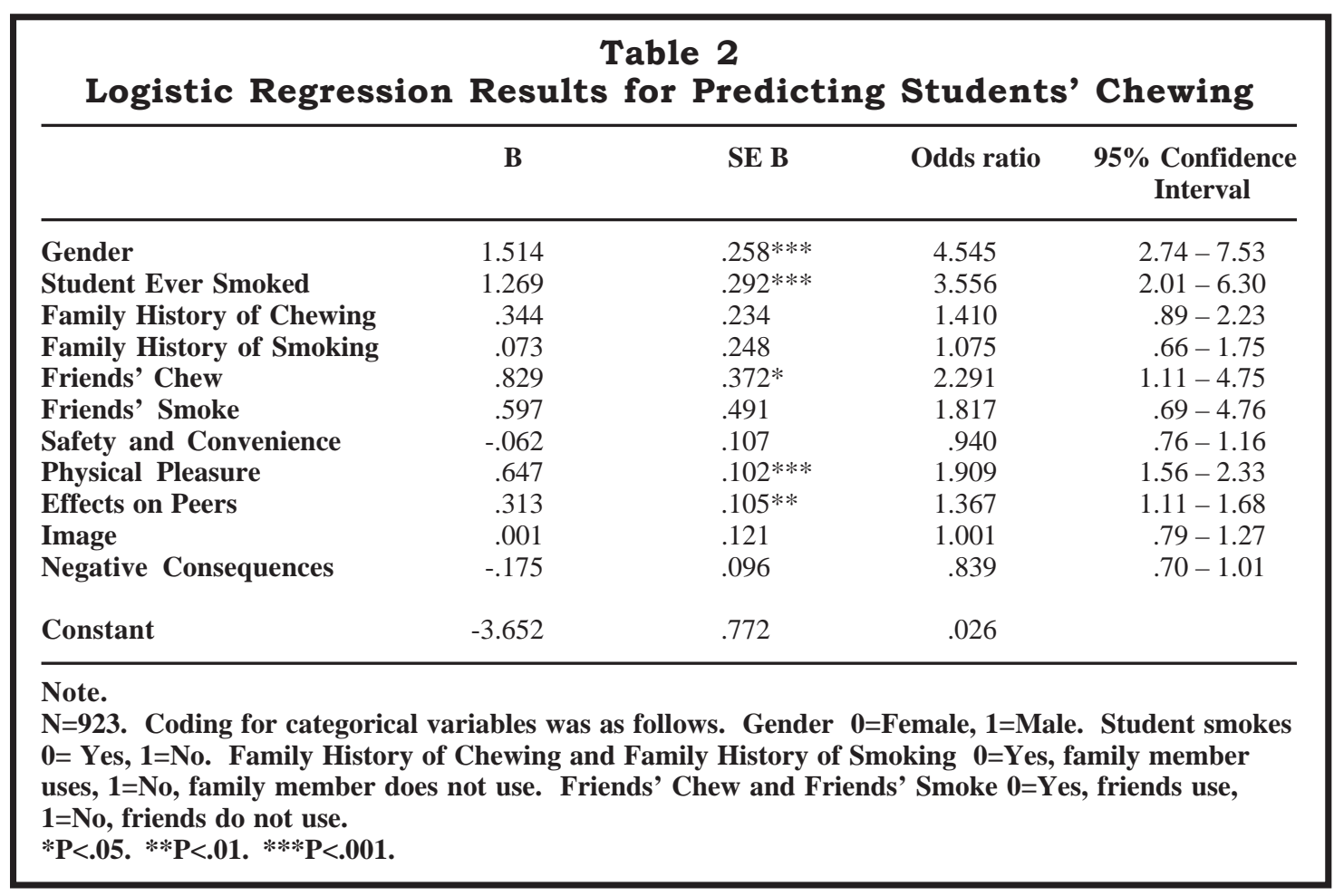




\section{Table 3 \\ Regression Results for Predicting Students' Use Intentions from Expectancies Controlling for Student Characteristics}

\begin{tabular}{lccc}
\hline & B & SE B & Beta \\
\hline Step 1 & & & \\
$\quad$ Gender & -.402 & .063 & $-.165^{* * *}$ \\
Student Smokes & .321 & .067 & $.131^{* * *}$ \\
Family History of Chewing & .111 & .063 & .044 \\
Family History of Smoking & -.063 & .060 & -.027 \\
Friends' Chew & .102 & .071 & .042 \\
Friends' Smoke & .053 & .088 & .017 \\
& & & \\
Step 2 & -.006 & .029 &. .007 \\
$\quad$ Safety and Convenience & .315 & .029 & $.380^{* * *}$ \\
Physical Pleasure & .141 & .026 & .017 \\
Effects on Peers & .020 & .037 & $-.075^{* *}$ \\
Image & -.076 & .026 & \\
Negative Consequences & & & \\
$\quad$ Constant 1.518 & & & \\
\hline
\end{tabular}

Note.

$\mathbf{R}^{2}=.25$ for Step 1. $\mathbf{R}^{2}$ change=.22 for Step 2. $\mathrm{N}=937$. Gender $\mathbf{0 = F e m a l e , ~} \mathbf{1 = M a l e}$. Student smokes $\mathbf{0}=$ Yes, $1=$ No. Family History of Chewing and Family History of Smoking $\mathbf{0}=$ Yes, family member uses, $1=$ No, family member does not use. Friends' Chew and Friends' Smoke $0=Y$ Yes, friends use, $1=$ No, friends do not use.

$* \mathbf{P}<$.05. $* * \mathbf{P}<.01$. $* * * \mathbf{P}<.001$.

influence use, we entered gender, whether the student smoked, family history of tobacco use, and friends' tobacco use as a block. Then, we entered the 5 expectancy variables as a block. The final regression model of all variables significantly predicted students' use $\left(\chi^{2}=362.46\right.$, $\mathrm{P}<.001)$. Estimated $\mathrm{R}^{2}$ values indicated a moderate to large effect size (Cox and Snell $\mathrm{R}^{2}=.33$; Nagelkerke $\mathrm{R}^{2}=.53$ ). The addition of expectancy beliefs significantly contributed to the model (Step $2 \chi^{2}=$ $127.00, \mathrm{P}<.001)$ with a substantial increase in estimated $\mathrm{R}^{2}$ (Cox and Snell increase .10; Nagelkerke increase .16). As shown in Table 2, students' gender, personal history of smoking, and friends' chewing significantly predicted ST use. Male students were $4^{1} / 2$ times more likely to use, students who had ever smoked were $3^{1} / 2$ times more likely to use, and students with friends who chewed were slightly more than 2 times as likely to use ST. Expectancy beliefs for physical pleasure and effects on peers significantly predicted use, with higher physical plea- sure expectancies increasing the odds of use by almost 2 and effects on peers expectancies increasing the odds of use by about $1^{1} / 3$.

We also examined the extent to which expectancies could predict students' intentions to use ST. Students were asked to indicate whether they thought they would try ST anytime in the next year on a 5-point Likert scale (1=definitely yes, $2=$ probably yes, $3=$ maybe, $4=$ probably not, and $5=$ definitely not). We conducted multiple regression analysis controlling for the effects of student and demographic characteristics by first entering gender, whether the student smoked, family history of tobacco use, and friends' tobacco use as a block. Then, we entered the 5 expectancy variables as a block. The final regression model of all variables significantly predicted students' reported intentions to try $\mathrm{ST}, \mathrm{R}=.68, \mathrm{R}^{2}=.47, \mathrm{~F}(11,930)$ $=73.14, \mathrm{P}<.001$. Expectancy beliefs made a significant contribution to predicting students' intentions beyond the effects of student characteristics, $\mathrm{R}^{2}$ change $=.22$, 
Table 4

Students' Mean Scores on Expectancies by Gender

\begin{tabular}{|c|c|c|c|c|c|c|c|}
\hline & \multirow[b]{2}{*}{ df } & \multicolumn{2}{|c|}{ Males } & \multicolumn{2}{|c|}{ Females } & \multirow[b]{2}{*}{$\mathbf{t}$} & \multirow{2}{*}{$\begin{array}{c}\text { Cohen's } \\
\text { d }\end{array}$} \\
\hline & & M & SD & M & SD & & \\
\hline Safety and Convenience & 868.51 & 4.89 & 1.48 & 5.72 & 1.17 & $9.67 * * *$ & .60 \\
\hline Physical Pleasure & 800.98 & 5.16 & 1.65 & 6.00 & 1.15 & $9.13^{* * *}$ & .57 \\
\hline Effects on Peers & 931.69 & 3.78 & 1.49 & 4.70 & 1.37 & $10.08 * * *$ & .62 \\
\hline Image & 791.56 & 5.98 & 1.15 & 6.49 & .79 & $7.92 * * *$ & .50 \\
\hline Negative Consequences & 940.90 & 2.25 & 1.24 & 1.98 & 1.16 & $-3.58 * * *$ & .23 \\
\hline
\end{tabular}

Note.

Males, $n=458$; Females, For Safety and Convenience and Effects on Peers, $n=518$; for all others, $\mathrm{n}=517$. For all tests, unequal variances were assumed. Cohen's $d=$ effect size in standard deviation units.

$* \mathbf{P}<.05 . * * \mathbf{P}<.01 . \quad * * * \mathbf{P}<.001$.

$\mathrm{F}(5,925)=75.20, \mathrm{P}<.001$. Table 3 shows that students' gender and personal history of smoking significantly predicted intentions to use ST, with males and those who reported having smoked expressing stronger intention to try. For expectancy beliefs, physical pleasure and effects on peers were the strongest predictors, with negative consequences making a smaller contribution to the prediction.

\section{Influences on the Development of ST Expectancies}

To better understand how ST expectancies develop, we examined differences in students' expectancies as a function of student characteristics and family and peer tobacco use. Gender exerted a strong influence on expectancies. Males had significantly more positive and less negative expectancies about ST than did females (Table 4). The effect sizes for all scales except negative consequences ranged from one half to almost two thirds of a standard deviation. These differences likely reflect, in part, the fact that males are much more likely to chew. Only 31 of 512 females in the sample chewed, compared to 144 of the 445 males. However, as indicated in Table 1, chewers regardless of gender differed from nonchewers by a much larger amount than males differed from females.

A personal history of smoking was linked to expectancies. As shown in Table 5, students who reported having ever smoked had significantly more positive and less negative expectancies about ST than did nonsmokers. The effect sizes for physical pleasure and effects on peers were approximately one half of a standard deviation. The remaining scales had effect sizes of about one third of a standard deviation.

Tobacco use by family members had inconsistent influences on ST expectancies. Table 6 shows that students who reported having someone in their family who chewed had significantly more positive and less negative expectancies than did those who did not. However, only the effects for physical pleasure and effects on peers had effect sizes of one fourth of a standard deviation or more, with neither exceeding .30. Students who reported having someone in their family who smoked (Table 6) differed significantly only for image expectancies; however, the effect size of .15 suggests a relatively small effect. Taken together, these findings suggest that the family history of tobacco use has only a small effect on students' expectancies about ST use.

Peer tobacco use exerted more influence on expectancies than family tobacco use did. Students were asked whether none, some, or all of their peers used tobacco in a 3-response question. Very few students reported that all their friends smoked or chewed; therefore, the some and all categories were combined for this 


\section{Students' Mean Scores on Expectancies by Smoking}

\begin{tabular}{|c|c|c|c|c|c|c|c|}
\hline & \multirow[b]{2}{*}{ df } & \multicolumn{2}{|c|}{ Smoker } & \multicolumn{2}{|c|}{ NonSmoker } & \multirow[b]{2}{*}{$\mathbf{t}$} & \multirow{2}{*}{$\begin{array}{c}\text { Cohen's } \\
\text { d }\end{array}$} \\
\hline & & $\mathbf{M}$ & SD & $\mathbf{M}$ & SD & & \\
\hline Safety and Convenience & 949.17 & 5.13 & 1.45 & 5.60 & 1.26 & $5.37 * * *$ & .34 \\
\hline Physical Pleasure & 973.78 & 5.28 & 1.59 & 6.04 & 1.17 & $8.58^{* * *}$ & .51 \\
\hline Effects on Peers & 924.48 & 3.92 & 1.49 & 4.73 & 1.39 & $8.72 * * *$ & .54 \\
\hline Image & 973.25 & 6.09 & 1.09 & 6.47 & .84 & $6.07 * * *$ & .37 \\
\hline Negative Consequences & 941.11 & 2.28 & 1.24 & 1.87 & 1.11 & $-5.45^{* * *}$ & .34 \\
\hline
\end{tabular}

Note.

Smoker, For Effects on Peers, $n=558$, for all others, $n=559$; Nonsmokers, For Safety and

Convenience, $n=416$; for all others, $n=417$. For all tests, unequal variances were assumed.

Cohen's $d=$ effect size in standard deviation units.

${ }^{*} \mathbf{P}<$.05. ${ }^{* *} \mathbf{P}<.01$. ${ }^{* * *} \mathbf{P}<.001$.

analysis. Students who reported having a friend or friends who chewed had significantly more positive and less negative expectancies toward ST use than did those who did not have a friend who chewed (Table 6). Effect sizes for all scales except negative consequences ranged from approximately one half to two thirds of a standard deviation. The effect size for negative consequences approached one third of a standard deviation.

Students who reported having a friend who smoked (Table 6) had significantly more positive and less negative expectancies than did those who did not have a friend who smoked. Effect sizes for all scales except safety and convenience ranged from about one third to one half of a standard deviation. The effect size for safety and convenience was approximately one fourth of a standard deviation. Taken together, these findings suggest that friends' use of tobacco influences students' expectancies about ST.

\section{DISCUSSION}

The relations of expectancies to ST use mirror those found between expectancies and smoking ${ }^{17-19}$ and expectancies and alcohol use, ${ }^{1,2,16}$ suggesting that expectancies have similar influences on ST use. Chewers and nonchewers differed substantially in their expectancies about ST. As would be expected, chewers expressed more positive and less negative expectancies. Expectancies contributed signifi- cantly to predicting current ST use even when the known predictors of gender, students' smoking history, and family or friends' tobacco use were considered. Expectancies also predicted students' intentions to use ST over and above gender, smoking, and family or peer tobacco use. Taken together, these findings suggest that expectancies play a meaningful role in students' current and future decision making about whether to use ST. As a result, public health education and prevention programs should consider addressing students' expectancies about ST as a way to impact use.

Because expectancies are learned ${ }^{1,2}$ and because ST use appears to begin around ages 12 to 14 (Grades 7 and 8), 8-10 education designed to encourage the development of more realistic expectancies needs to begin before age 12 and continue through the time of onset.

The finding that expectancies predicted intention to use ST, even when other predictors of ST use were considered, suggests that intentions could be a useful focus for those developing prevention/ educational programs. Although there is a growing body of work describing the relationship between tobacco-related intentions and behaviors, ${ }^{17-19}$ much less has been done to evaluate the effectiveness of educational programs designed to reform expectancies.

Expectancies were influenced by students' gender and smoking history. Males 
Table 6

Students' Mean Scores on Expectancies by Family and Peer Tobacco Use

\begin{tabular}{|c|c|c|c|c|c|c|c|}
\hline & \multirow[b]{2}{*}{ df } & \multicolumn{2}{|c|}{ Yes } & \multicolumn{2}{|c|}{ No } & \multirow[b]{2}{*}{$\mathbf{t}$} & \multirow{2}{*}{$\begin{array}{c}\text { Cohen's } \\
\text { d }\end{array}$} \\
\hline & & M & SD & $\mathbf{M}$ & SD & & \\
\hline \multicolumn{8}{|l|}{ Family Member Chews } \\
\hline Safety and Convenience & 705.68 & 5.16 & 1.46 & 5.44 & 1.33 & $2.97 * *$ & .20 \\
\hline Physical Pleasure & 686.79 & 5.33 & 1.57 & 5.77 & 1.38 & $4.34 * * *$ & .29 \\
\hline Effects on Peers & 718.76 & 4.03 & 1.56 & 4.41 & 1.45 & $3.77 * * *$ & .25 \\
\hline Image & 676.02 & 6.13 & 1.09 & 6.33 & .95 & $2.86 * *$ & .20 \\
\hline Negative Consequences & 770.35 & 2.23 & 1.19 & 2.04 & 1.21 & $-2.38^{*}$ & .16 \\
\hline \multicolumn{8}{|l|}{ Family Member Smokes } \\
\hline Safety and Convenience & 948 & 5.35 & 1.35 & 5.34 & 1.41 & -.06 & .00 \\
\hline Physical Pleasure & 949 & 5.55 & 1.43 & 5.73 & 1.51 & 1.85 & .12 \\
\hline Effects on Peers & 948 & 4.21 & 1.49 & 4.39 & 1.50 & 1.88 & .12 \\
\hline Image & 949 & 6.19 & 1.03 & 6.34 & .96 & $2.26^{*}$ & .15 \\
\hline Negative Consequences & 949 & 2.12 & 1.17 & 2.06 & 1.24 & -.78 & .05 \\
\hline \multicolumn{8}{|l|}{ Friends Chew } \\
\hline Safety and Convenience & 780.58 & 5.09 & 1.44 & 5.82 & 1.14 & $8.50 * * *$ & .52 \\
\hline Physical Pleasure & 901.34 & 5.31 & 1.57 & 6.20 & 1.02 & $10.58 * * *$ & .68 \\
\hline Effects on Peers & 712.59 & 3.92 & 1.47 & 4.99 & 1.30 & $11.53 * * *$ & .71 \\
\hline Image & 853.40 & 6.10 & 1.08 & 6.57 & .76 & $7.89 * * *$ & .47 \\
\hline Negative Consequences & 688.68 & 2.23 & 1.22 & 1.84 & 1.12 & $-4.91 * * *$ & .32 \\
\hline \multicolumn{8}{|l|}{ Friends Smoke } \\
\hline Safety and Convenience & 314.26 & 5.27 & 1.40 & 5.60 & 1.31 & $3.01 * *$ & .24 \\
\hline Physical Pleasure & 352.28 & 5.49 & 1.50 & 6.09 & 1.24 & $5.68 * * *$ & .40 \\
\hline Effects on Peers & 314.43 & 4.11 & 1.48 & 4.94 & 1.40 & $7.26^{* * *}$ & .55 \\
\hline Image & 447.37 & 6.17 & 1.05 & 6.61 & .69 & $7.20 * * *$ & .44 \\
\hline Negative Consequences & 319.15 & 2.18 & 1.21 & 1.79 & 1.12 & $-4.29 * * *$ & .32 \\
\hline
\end{tabular}

Note.

For Family Member Chews: Yes, $n=363$; No, For Safety and Convenience and Effects on Peers, n=609; for all others, $n=610$. For Family Member Smokes: Yes, For Safety and Convenience, $n=550$; for all others, $n=551$; No, For Effects on Peers, $n=399$; for all others, $n=400$. For Family Member Chews, unequal variances were assumed for all tests. For Family Member Smokes, equal variances were assumed for all tests. For Friends Chew: Yes, For Effects on Peers, $n=650$; for all others, $n=651$; No, For Safety and Convenience, $n=320$; for all others, $n=321$. For Friends Smoke, Yes, $n=764$; No, For Safety and Convenience, $n=195$; for all others, $n=196$. For all tests except Family Member Smokes, unequal variances were assumed. Cohen's $d=$ effect size in standard deviation

were much more likely to use ST and had considerably stronger positive expectancies for ST use. Also, student smoking strongly influenced expectancies about chewing, with smokers expressing more positive and less negative ST expectancies. These findings confirm the potentially important links between smoking and chewing beliefs and behaviors..$^{3,9,10}$
Expectancies were also influenced by whether student's family or peers smoked or chewed, but peer use of tobacco had far more influence on expectancies than did family member use. This finding also confirms findings of earlier studies. ${ }^{9,12-14}$ These findings help place in perspective the relative importance of family and peer influences. Clearly family influences 
are important, but not nearly as important as peer influences. The greater contribution of peer influence, compared to family influence, suggests priorities for the educational planner.

Finally, expectancies about long-term health consequences of ST such as cancer did not form a coherent factor in the development of the ST expectancy instrument. ${ }^{23}$ Further research is needed to clarify the role of expectancies concerning serious and long-term health consequences in ST use decision making. Notwithstanding these limitations, this study contributes to our understanding of adolescent ST-use and the role that expectancies about ST play in decisions to use ST.

This study is limited by the examination of one rural convenience sample. The extent to which study findings might generalize to urban or suburban populations or to other rural populations is not known. Also, the study is limited in that only self-report measures were used. Certainly, more independent measurement of family and peer tobacco use and attitudes would allow greater precision in determining their influences on expectancies. Nevertheless, this study is one of the few that has attempted to describe ST use among a rural Midwestern sample of high school students. The incidence of ST use among young males in urban states is significantly lower than that of cigarette use, but it is still significant when the base population is considered. In Massachusetts, for example, 2001 YRBS data suggest that $7.4 \%$ of the males had chewed tobacco in the previous 30 days. In the largely rural states of Wyoming, Montana, South Dakota, Iowa, and Nebraska, male use of ST in the last 30 days was $28.6 \%$, $25.2 \%, 24.3 \%, 20.0 \%$, and $16.8 \%$, respectively. Female use of ST continues to be lower than male use in all states. ${ }^{24}$

This study identified positive expectancies for ST as seen by ST users and potential users. The perceived utility of ST use suggests that as efforts to discourage cigarette smoking increase, there is a distinct possibility of inadvertently encouraging ST use. Added to this, the significant number of young people already using ST should encourage prevention researchers to pay more attention to this behavior.

\section{Acknowledgment}

This research was supported by the
Nebraska Department of Health \& Human Services Cancer and Smoking Disease Research Fund (\#2001-08B). Also, we wish to acknowledge the contribution of Michelle Maas to the editing and organization of this paper.

\section{REFERENCES}

1.Goldman MS, Brown SA, Christiansen BA. Expectancy theory: thinking about drinking. In. Blane HT, Leonard KE, (Eds). Psychological Theories of Drinking and Alcoholism. New York: Guilford Press, 1987:181-226.

2.Goldman MS, Del Boca FK, Darkes J. Alcohol expectancy theory: The application of cognitive neuroscience. In. Leonard $\mathrm{KE}$, Blane $\mathrm{HT}$, (Eds). Psychological Theories of Drinking and Alcoholism, $2^{\text {nd }}$ ed. New York: Guilford Press, 1990:203-246.

3.Hu FB, Hedeker D, Day LE, et al. Patterns of use of smokeless tobacco and the unidimensional model of drug involvement. Addict Behav. 1997;22(2):257-261.

4.National Center for Chronic Disease Prevention and Health Promotion. Detailed results: tobacco use United States trend (on-line). Available at: http://www.cdc.gov/nccdphp/ dash/yrbs/2001/youth01online.htm. Accessed January 21, 2004.

5.Centers for Disease Control and Prevention. Tobacco use among middle and high school students - United States, 2002 (on-line). MMWR. 2003;52(45):1096-1098. Available at: http: $\quad$ www.cdc.gov/mmwr/preview / mmwrhtml/mm5245a2.htm. Accessed January $21,2004$.

6.National Center for Chronic Disease Prevention and Health Promotion. Detailed results: tobacco use United States 2001 by sex (online). Available at: http://www.cdc.gov/ $\mathrm{n} \mathrm{c} \mathrm{c} \mathrm{d} \mathrm{p} \mathrm{h} \mathrm{p} \mathrm{/} \mathrm{d} \mathrm{a} \mathrm{s} \mathrm{h} \mathrm{/} \mathrm{y} \mathrm{r} \mathrm{b} \mathrm{s} \mathrm{/} 2001 /$ youth01online.htm. Accessed January 21, 2004.

7.Centers for Disease Control and Prevention. Youth tobacco surveillance - United States, 1998-1999. MMWR. 2000;49(Suppl 10):4648.

8.Riley WT, Kaugars GE, Grisius TM, et al. Adult smokeless tobacco use and age of onset. Addict Behav. 1996;21(1):135-138.

9.Creath CJ, Wright JT, Wisniewski JF. Characteristics of smokeless tobacco use among high school football players as related to type of smokeless tobacco and period of use. J Drug Educ. 1992;22(1):69-85.

10.Simon TR, Sussman S, Dent CW, et al. Prospective correlates of exclusive or combined adolescent use of cigarettes and smokeless tobacco: a replication-extension. Addict Behav. 1995;20(4):517-524.

11.Riley WT, Barenie JT, Woodard CE, et al. Perceived smokeless tobacco addiction among adolescents. Health Psychol. 1996;15(4):289292. 
12.Boyle RG, Claxton AJ, Forster JL. The role of social influences and tobacco availability on adolescent smokeless tobacco use. J Adolesc Health. 1997;20:279-285.

13.Horn KA, Gao X, Dino GA, et al. Determinants of youth tobacco use in West Virginia: a comparison of smoking and smokeless tobacco use. Am J Drug Alcohol Abuse. 2000;26(1):125-138.

14.Kury SP, Rodrigue JR, Perri MG. Smokeless tobacco and cigarettes: differential attitudes and behavioral intentions of young adolescents toward a hypothetical new peer. $J$ Clin Child Psychol. 1998;27(4):415-422.

15.Booth-Butterfield M, Anderson R, Williams K. Perceived messages from schools regarding adolescent tobacco use. Communication Education. 2000;49(2):196-205.

16. Kline RB. Eight-month predictive validity and covariance structure of the alcohol expectancy questionnaire for adolescents (AEQA) for junior high school students. J Stud Alcohol. 1996;57:396-405.

17. Cohen LM, McCarthy DM, Brown SA, et al. Negative affect combines with smoking outcome expectancies to predict smoking behavior over time. Psychol Addict Behav. 2002;16(2): 91-97.

18. Hine DW, McKenzie-Richer A, Lewko J, et al. A comparison of the mediation properties of four adolescent smoking expectancy measures. Pscyol Addict Behav. 2002;16(3):187195.

19. Wetter DW, Smith SS, Kenford SL, et al. Smoking outcome expectancies: factor structure, predictive validity and discriminant validity. J Abnorm Psychol. 1994:103(4):801-811.

20.Stacy AW, Dent CW, Sussman S, et al. Expectancy accessibility and the influence of outcome expectancies on adolescent smokeless tobacco use. J Appl Psychol. 1990;20(10):802817.

21.Gerber RW, Newman IM, Martin GL. Early adolescent tobacco chewing: an application of the theory of reasoned action. $J$ Sch Health. 1988;58(10):410-413

22.Kann L, Kinchen SA, Williams BI, et al. Youth risk behavior surveillance - United States, 1999. MMWR. 2000; 49(SS-5):1-95.

23. Newman IM. Final Report: Smokeless Tobacco Use Expectancies Among Nebraska Adolescents (Research Grant \#2001-08B). Lincoln, NE: Nebraska Department of Health \& Human Services, Office of Cancer and Smoking Disease Research, P. O. Box 95026, Lincoln, Nebraska 68509-5026.

24.Centers for Disease Control and Prevention. Surveillance summaries, June 28, 2002. MMWR. 2002:51(No. SS-4):36. 